Polymer Journal, Vol. 2, No. 6, pp 783-788 (1971)

\title{
Room-Temperature Polycondensation of S, S-Dithioesters with Diamines
}

\author{
Kohei SANui and Naoya Ogata \\ Department of Chemistry, Sophia University, Kioi-cho, Chiyoda-ku, Tokyo, Japan.
}

(Received May 13, 1971)

\begin{abstract}
The polycondensation reaction of s, s-dithiocarboxylic acid esters with diamines took place at room temperature to yield polyamide in solution. The reactivity of aromatic S, S-dithioester with aliphatic diamine was higher than that of aliphatic S, S-dithioester and the reaction of S, S-dithioester with aromatic diamine was much slower than that with aliphatic diamine. Solvents greatly influenced the rate of the polycondensation and an inorganic salt such as lithium chloride accelerated the reaction. Polyisophthalamide having an inherent viscosity of 1.06 was obtained in dimethyl sulfoxide in the presence of lithium chloride at $30^{\circ} \mathrm{C}$.
\end{abstract}

KEY WORDS Room-temperature Polycondensation / Polyamide /

S, S-Dithioester / Diamine / Solvent Effect / Chelating Complex /

The polycondensation reaction of dicarboxylic acid with diamine is usually carried out in a molten state at high temperature above the melting point of the resulting polyamide with a continuous elimination of water out of the reaction phase since the polycondensation reaction phase since the polycondensation reaction is controlled by chemical equilibrium.

Thio acid was found ${ }^{1,2}$ to be a. very active acylating agent which is useful in peptide synthesis. Also, it was previously found ${ }^{3,4}$ that the aminolysis of s-thioester by $n$-butylamine took place in aqueous solution at $0^{\circ} \mathrm{C}$ to yield an amide compound. Therefore, S-thioester of carboxylic acid is expected to react also with amine at a relatively low temperature to form an amide compound as follows:

$$
\begin{array}{r}
\mathrm{R}-\mathrm{COS}-\mathrm{R}^{\prime}+\mathrm{R}^{\prime \prime}-\mathrm{NH}_{2} \\
\longrightarrow \mathrm{R}-\mathrm{CONH}-\mathrm{R}^{\prime \prime}+\mathrm{R}^{\prime}-\mathrm{SH}
\end{array}
$$

This condensation reaction was extended to the synthesis of polyamide in an attempt to ob- tain polyamide in a mild reaction condition without heating.

\section{EXPERIMENTAL}

\section{Synthesis of Thioesters}

One mol of dicarboxylic acid chloride was: added in small amounts to an excess of $n$-propyl mercaptan which was cooled below $0^{\circ} \mathrm{C}$. The mixture was kept at room temperature and stirred for $15 \mathrm{hr}$ and then heated under reflux for at least $24 \mathrm{hr}$. After the reaction solution was cooled to room temperature, the solution was poured into water, followed by extraction with benzene.

After the benzene solution was washed once with $10-\%$ sodium hydroxide solution and then with water, it was dried over anhydrous sodium sulfate. After the removal of benzene, distillation of thioesters was repeated three times for purification. Physical constants of the thioesters

\begin{tabular}{|c|c|c|c|c|c|c|}
\hline \multirow{2}{*}{ Thioester } & \multirow{2}{*}{ Yield, $\%$} & \multirow{2}{*}{$\mathrm{bp},{ }^{\circ} \mathrm{C}$} & \multicolumn{2}{|c|}{$\mathrm{C}, \%$} & \multicolumn{2}{|c|}{$\mathrm{H}, \%$} \\
\hline & & & Found & Calcd & Found & Calcd \\
\hline $\mathrm{CH}_{3} \mathrm{COSPr}$ & 61 & $138-140$ & 50.70 & 50.83 & 8.62 & 8.53 \\
\hline $\operatorname{PrSCO}\left(\mathrm{CH}_{2}\right)_{4} \mathrm{COSPr}$ & 55 & $144-145 / 3 \mathrm{mmHg}$ & 54.61 & 54.95 & 8.23 & 8.45 \\
\hline $\operatorname{PrSCO}\left(\mathrm{CH}_{2}\right)_{8} \mathrm{COSPr}$ & 51 & $179-181 / 3 \mathrm{mmHg}$ & 60.45 & 60.35 & 9.61 & 9.50 \\
\hline COSPr & 57 & $181-182 / 3 \mathrm{mmHg}$ & 60.13 & 59.56 & 6.58 & 6.43 \\
\hline
\end{tabular}

Table I. Physical constants of S, S-dithioesters. 


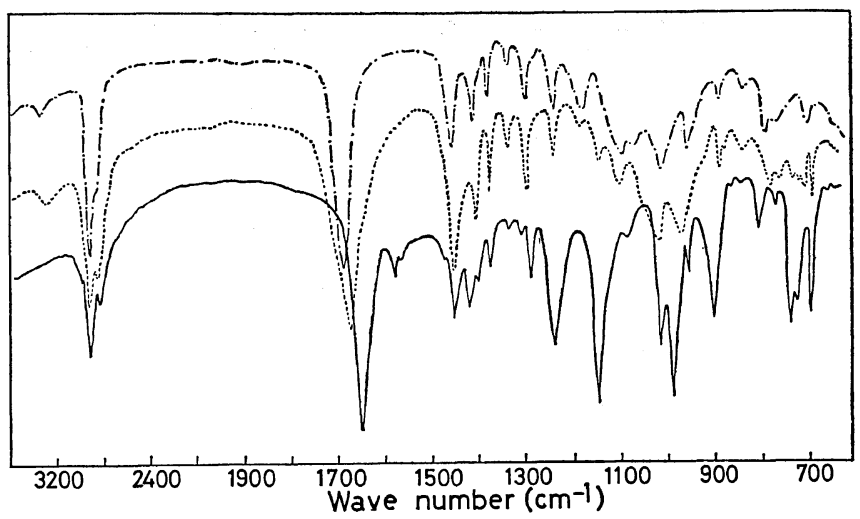

Figure 1. Infrared spectra of S, S-dipropyl dithioesters.

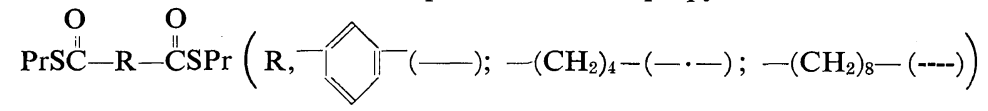

obtained are summarized in Table $I$ and their infrared spectra are shown in Figure 1.

\section{Solution Polycondensation}

A given amount of S, S-dipropyl thioesters and diamines was dissolved in various solvents in the presence of $5 \mathrm{~mol} \%$ of lithium ethoxide and the solution was kept at a constant temperature. The rate of the polycondensation reaction was followed by titration of residual amine in the solution. After the reaction was completed, the solution was poured into an excess of water and the resulting polymers were filtered, followed by washing with water and drying. The solution viscosity of polymers was determined in concentrated sulfuric acid at $30^{\circ} \mathrm{C}$. The polymers were identified as polyamides from their elementary analyses, melting points, and infrared spectra.

\section{RESULTS AND DISCUSSION}

\section{Model Reaction}

Rates of condensation reaction of S-propyl thioacetate with $n$-butylamine were determined in various solvents and results are shown in Figure 2, which indicates that the condensation reaction takes place at $30^{\circ} \mathrm{C}$ to yield $N$-(n-butyl) acetamide and the solvent effect on the condensation rate is observed.

$$
\begin{aligned}
& \mathrm{CH}_{3} \mathrm{COS}-\mathrm{Pr}+\mathrm{Bu}-\mathrm{NH}_{2} \\
& \longrightarrow \mathrm{CH}_{3} \mathrm{CONH}-\mathrm{Bu}+\mathrm{Pr}-\mathrm{SH}
\end{aligned}
$$

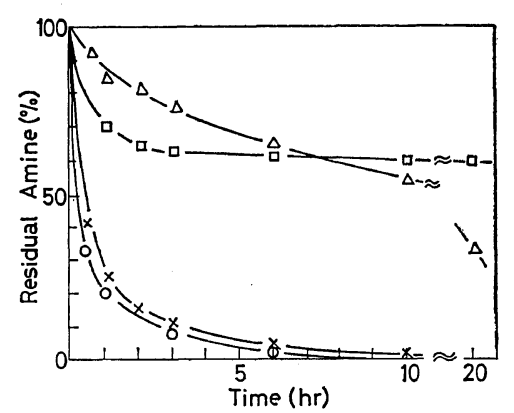

Figure 2. Rates of the condensation reaction of s-propyl thioacetate with $n$-butylamine in various solvents: monomer concn, $1 \mathrm{~mol} / l ; 30^{\circ} \mathrm{C}$; catalyst, $5 \mathrm{~mol} \%$ of EtOLi; $\bigcirc, \mathrm{DMF} ; \times, \mathrm{DMSO} ; \triangle$, THF; $\square, \mathrm{C}_{2} \mathrm{H}_{5} \mathrm{OH}$.

Dimethylformamide (DMF) and dimethy sulfoxide(DMSO) are effective solvents to cause the reaction to occur in a quantitative yield within $10 \mathrm{hr}$, while in ethanol the reaction apparently reaches an equilibrium which could arise from the exchange reaction of thioester with ethanol to yield ester. It was found that the condensation reaction of S-thioester with amine shows a significant shift towards an amide formation without the apparent equilibrium which is observed in the condensation reactions of ordinary esters with amine.

\section{Polycondensation of S,S-Dithioesters with Diamines}

Rates of the polycondensation reaction of aliphatic or aromatic S, S-dithioesters with hexa- 


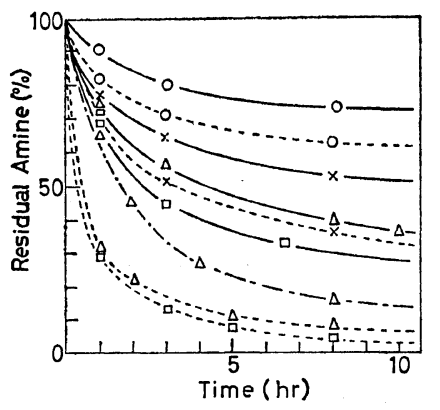

Figure 3. Rates of the polycondensation reaction of s, s-dithioesters with hexamethylenediamine in various solvents: monomer concn, $0.5 \mathrm{~mol} / l ; 30^{\circ} \mathrm{C}$; catalyst, $5 \mathrm{~mol} \%$ of EtOLi; $\mathrm{O}, \mathrm{EtOH} ; \times$, THF; $\triangle$, DMF; $\square$, DMSO; - $\operatorname{PrSCO}\left(\mathrm{CH}_{2}\right)_{4} \mathrm{COSPr}$; -.., $\operatorname{PrSCO}\left(\mathrm{CH}_{2}\right)_{8} \mathrm{COSPr}$;<smiles>CCOC(=O)c1cccc(O[R]#CPCC)c1</smiles>

methylenediamine were determined in various solvents and results are summarized in Figure 3 and Table II.

Polymers were identified as polyamides from their infrared spectra, and their melting point and elementary analyses are shown in Table III.
It was found that the polycondensation reaction took place at room temperature to yield polyamide in a good yield by simply mixing $S$, S-dithioesters with diamines in solution and the rate of the polycondensation reaction was greatly influenced by the solvent, as shown in Figure 3. A solvent effect similar to that of the model reaction was observed and DMF or DMSO were found to be the best solvents for the polycondensation. Figure 3 also indicates that the reactivities of S, S-dithioesters PrSCO- $\mathrm{R}-\mathrm{COS}$ $\operatorname{Pr}$ with hexamethylenediamine decrease in the following order:

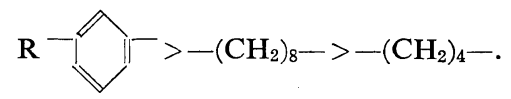

The carbonyl absorption band of these S, Sdithioesters in their infrared spectra was observed at $1660 \mathrm{~cm}^{-1}$ for $\mathrm{S}, \mathrm{S}$-dithioisophthalate, $1680 \mathrm{~cm}^{-1}$ for S, S-dithiosebacate and $1690 \mathrm{~cm}^{-1}$ for S, S-dithioadipate, respectively, as can be seen in Figure 1. Since the carbonyl absorption bands of s-thioester were found at a lower frequency than that of ordinary esters, which appears near $1720 \mathrm{~cm}^{-1}$, it is concluded that the carbonyl group of S-thioesters is more polarized,

Table II. Solution polycondensation of S, S-dithioesters with hexamethylenediamine in various solvents ${ }^{a}$

\begin{tabular}{|c|c|c|c|c|c|}
\hline $\operatorname{PrSCO}-\mathrm{R}-\mathrm{COSPr}$ & Solvent & Concn, $\mathrm{mol} / \mathrm{l}$ & Temp, ${ }^{\circ} \mathrm{C}$ & Yield, $\%$ & $\eta_{\text {inh }}$ \\
\hline$-\left(\mathrm{CH}_{2}\right)_{4}-$ & EtOH & 0.5 & 30 & 18 & 0.09 \\
\hline " & THF & 0.5 & 30 & 69 & 0.09 \\
\hline " & DMF & 0.5 & 30 & 76 & 0.11 \\
\hline " & $\mathrm{DMSO}^{\mathrm{b}}$ & 0.5 & 30 & 86 & 0.12 \\
\hline " & DMSO & 0.5 & 30 & 62 & 0.13 \\
\hline " & DMSO & 0.5 & 60 & 81 & 0.17 \\
\hline$\left(\mathrm{CH}_{2}\right)_{8}-$ & DMF & 0.5 & 30 & 94 & 0.12 \\
\hline " & DMSO & 0.5 & 60 & 100 & 0.15 \\
\hline & EtOH & 0.5 & 30 & 42 & 0.08 \\
\hline " & THF & 0.5 & 30 & 86 & 0.11 \\
\hline " & DMF & 0.5 & 30 & 91 & 0.19 \\
\hline " & DMSO & 0.125 & 30 & 84 & 0.17 \\
\hline " & DMSO & 0.25 & 30 & 94 & 0.22 \\
\hline " & $\mathrm{DMSO}^{\mathrm{b}}$ & 0.5 & 30 & 68 & 0.16 \\
\hline " & DMSO & 0.5 & 30 & 96 & 0.32 \\
\hline " & DMSO & 0.5 & 60 & 89 & 0.33 \\
\hline " & DMSO & 1.0 & 30 & 100 & 0.42 \\
\hline
\end{tabular}

a Catalyst, EtOLi, 5 mol\%; Time, 3 day.

b No catalyst. 


\section{K. Sanui and N. Ogata}

Table III. Polyamides from S, S-dithioesters with diamines.

\begin{tabular}{|c|c|c|c|c|c|c|c|}
\hline \multirow{2}{*}{ Polyamide } & \multirow{2}{*}{$\mathrm{mp},{ }^{\circ} \mathrm{C}-$} & \multicolumn{2}{|c|}{ C, $\%$} & \multicolumn{2}{|c|}{$\mathrm{H}, \%$} & \multicolumn{2}{|c|}{$\mathrm{N}, \%$} \\
\hline & & Found & Calcd & Found & Calcd & Found & Calcd \\
\hline$-\left[-\mathrm{CO}\left(\mathrm{CH}_{2}\right)_{4} \mathrm{CONH}\left(\mathrm{CH}_{2}\right)_{6} \mathrm{NH}-\right]-$ & $238-240$ & 62.95 & 63.68 & 9.68 & 9.80 & 11.96 & 12.38 \\
\hline$-\left[-\mathrm{CO}\left(\mathrm{CH}_{2}\right)_{8} \mathrm{CONH}\left(\mathrm{CH}_{2}\right)_{6} \mathrm{NH}-\right]-$ & $220-225$ & 67.41 & 68.04 & 10.52 & 10.71 & 9.57 & 9.92 \\
\hline $\mathrm{CONH}(\mathrm{CH}$ & $215-220$ & 67.85 & 68.27 & 6.98 & 7.37 & 11.21 & 11.37 \\
\hline & & 71.93 & 72.72 & 4.02 & 4.27 & 8.05 & 8.48 \\
\hline
\end{tabular}

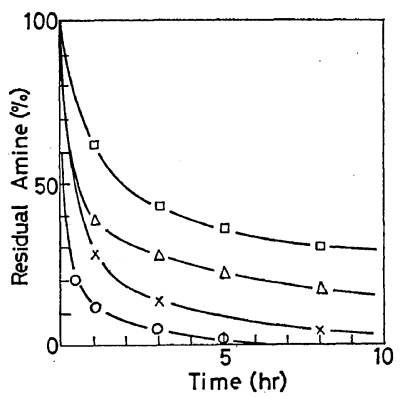

Figure 4. Rates of the polycondensation reaction of S, S-dipropyl dithioisophthalate with hexamethylenediamine in various concentrations in DMSO: $30^{\circ} \mathrm{C}$, catalyst, $5 \mathrm{~mol} \%$ of EtOLi; $\bigcirc, 1.0 \mathrm{~mol} / \mathrm{l}$, $\times ; 0.5 \mathrm{~mol} / l, \triangle, 0.25 \mathrm{~mol} / l, \square, 0.125 \mathrm{~mol} / l$. due to the thioalkyl group. Since the shift in the carbonyl absorption band was particularly noted in S, S-dithioisophthalate which caused the polycondensation with diamine at a faster rate and the order of the carbonyl shift corresponded to the polycondensation rate of S, S-dithioesters, it is presumed that the attacking of nucleophiles such as diamines takes place more readily as the polarization of the carbonyl group is more extensive.

The reaction temperature had no effect on the molecular weight of the polyamides obtained, as can be seen in Table II.

Table IV. Solution polycondensation of S, S-dithioesters with hexamethylenediamine in the presence of various inorganic salts ${ }^{\mathrm{a}}$

\begin{tabular}{|c|c|c|c|c|c|c|}
\hline \multirow{2}{*}{ Dithioester } & \multirow{2}{*}{ Solvent } & \multirow{2}{*}{$\begin{array}{l}\text { Inorganic } \\
\text { salt }\end{array}$} & \multirow{2}{*}{$\begin{array}{l}\text { Amount of } \\
\text { salt, wt } \%\end{array}$} & \multirow{2}{*}{$\begin{array}{c}\text { Concn of } \\
\text { monomer, } \\
\mathrm{mol} / l\end{array}$} & \multicolumn{2}{|c|}{ Polymer } \\
\hline & & & & & Yield, \% & $\eta_{\text {inh }}$ \\
\hline $\operatorname{PrSCO}\left(\mathrm{CH}_{2}\right)_{4} \mathrm{COSPr}$ & DMF & none & 0 & 0.5 & 76 & 0.11 \\
\hline " & DMF & $\mathrm{LiCl}$ & 5 & 0.5 & 65 & 0.11 \\
\hline " & NMP & $\mathrm{LiCl}$ & 5 & 0.5 & 48 & 0.13 \\
\hline $\mathrm{PrSCO}^{-}$ & DMF & none & 0 & 0.5 & 91 & 0.19 \\
\hline " & DMF & $\mathrm{I}_{2}$ & 5 & 0.5 & 0 & - \\
\hline " & DMF & $\mathrm{FeCl}_{3}$ & 5 & 0.5 & 0 & 一 \\
\hline " & DMF & $\mathrm{HgO}$ & 5 & 0.5 & 100 & 0.14 \\
\hline " & DMF & $\mathrm{MgCl}_{2}$ & 5 & 0.5 & 0 & - \\
\hline " & DMF & $\mathrm{Mg}(\mathrm{AcAc})_{2}$ & 5 & 0.5 & 0 & - \\
\hline "I. & DMF & $\mathrm{LiCl}$ & 2 & 0.5 & 88 & 0.23 \\
\hline " & DMF & $\mathrm{LiCl}$ & 5 & 0.5 & 92 & 0.21 \\
\hline " & DMF & $\mathrm{CaCl}_{2}$ & 5 & 0.5 & 95 & 0.36 \\
\hline " & NMP & $\mathrm{LiCl}$ & 5 & 0.5 & 95 & 0.19 \\
\hline " & DMSO & none & 0 & 0.5 & 96 & 0.32 \\
\hline " & DMSO & none & 0 & 1.0 & 100 & 0.42 \\
\hline "I & DMSO & $\mathrm{LiCl}$ & 2 & 0.5 & 98 & 0.46 \\
\hline " & DMSO & $\mathrm{LiCl}$ & 5 & 0.5 & 95 & 0.47 \\
\hline "I & DMSO & $\mathrm{LiCl}$ & 5 & 1.0 & 95 & 1.06 \\
\hline
\end{tabular}

a Polycondensation was carried out at $30^{\circ} \mathrm{C}$ for 3 days in the presence of $5 \mathrm{~mol} \%$ of lithium ethoxide. 


\section{Room-Temperature Polycondensation}

The polycondensation rate of S, S-dipropyl dithioisophthalate with hexamethylenediamine was determined in various monomer concentrations in DMSO, as shown in Figure 4. Figure 4 and Table II indicate that both the rate and the molecular weight of resulting polyamides are increased with increasing monomer concentration, respectively. Polyamide having the inherent viscosity of 0.42 was quantitatively obtained in the monomer concentration of $1 \mathrm{~mol} / l$ at $30^{\circ} \mathrm{C}$.

Although the yield of polyamide reached 100$\%$, the inherent viscosity of the resulting polyamide did not exceed 0.5 and the reason might be ascribed to the heterogeneous reaction phase, since polyamide was gradually precipitated out of the solution in DMSO as the polycondensation reaction proceeded. Therefore, inorganic salts which form a chelating complex with the amide group were added in the reaction phase in order to cause the reaction to proceed in a homogeneous phase by dissolving polyamide by means of the formation of a chelating complex.

Table IV summarizes results of the polycondensation reaction in the presence of inorganic salts. When lithium chloride or calcium chloride were added to the solution by the amount of $5 \mathrm{wt} \% /$ solvent, the polycondensation reaction proceeded in a homogeneous phase without the precipitation of polyamide and a very viscous solution was obtained after the completion of polycondensation, When $\mathrm{I}_{2}, \mathrm{FeCl}_{3}, \mathrm{HgO}$, $\mathrm{MgCl}_{2}$ or magnesium acetyl acetonate were added in the solution, only an oily product was obtained without the formation of polyamide, while lithium chloride or calcium chloride promoted the polycondensation reaction of S, S-dithioisophthalate and, in particular, a high molecular weight polyamide having the inherent viscosity of 1.06 was ovtainued in thie monomer concentration of $1 \mathrm{~mol} / l$ in DMSO in the presence of lithium chloride. However, no accelerating effect of lithium chloride was observed for the polycondensation of aliphatic s, s-dithioester.

Figure 5 shows the polycondensation rate of s, s-dipropyl dithioisophthalate with hexamethylenediamine in the presence of lithium chloride or calcium chloride, where it is seen that the rate is greatly accelerated by these inorganic salts with the completion of the reaction within $5 \mathrm{hr}$. Calcium chloride in particular accelerates the reaction. The quantity of these inorganic salts influences both the polycondensation rate and molecular weight of the resulting polyamide.

The effect or inorganic salts on the polycondensation reaction is not yet clear. The effect might be attributed either to the chelating complex formation at the reaction stage, which might increase the reactivity of functional group, or to the solvating effect of the resulting

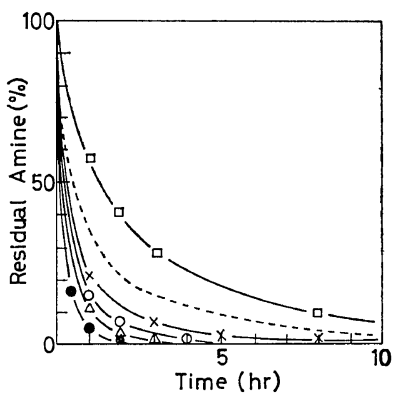

Figure 5. Rates of the polycondensation reaction of S,S-dipropyl dithioisophthalate with hexamethylenediamine in the presence of inorganic salts (-): monomer concn, $0.5 \mathrm{~mol} / l$ in DMF or DMSO; $30^{\circ} \mathrm{C}$; catalyst, $5 \mathrm{~mol} \%$ of EtOLi; $\bigcirc$, $\mathrm{LiCl}(5 \mathrm{wt} \%)$ in DMF; $\times, \mathrm{LiCl}(2 \mathrm{wt})$ in DMF; -, $\mathrm{CaCl}_{2}(5 \mathrm{wt} \%)$ in DMF, $\triangle, \mathrm{LiCl}(5 \mathrm{wt} \%)$ in Divíso; $\square, \mathrm{LiCl}(5 \mathrm{wi} \%)$ in NMP, (---) none.

Table V. Solution polycondensation of S, S-dipropyl dithioisophthalate with 4, 4-diaminodiphenyl ether

\begin{tabular}{|c|c|c|c|c|c|}
\hline \multirow{2}{*}{ Solvent } & \multirow{2}{*}{ Inorganic salt } & \multirow{2}{*}{ Temp, ${ }^{\circ} \mathrm{C}$} & \multirow{2}{*}{ Time, day } & \multicolumn{2}{|c|}{ Polymer } \\
\hline & & & & Yield, $\%$ & $\eta_{\text {inh }}$ \\
\hline DMF & none & 30 & 7 & 61 & 0.08 \\
\hline DMSO & none & 60 & 7 & 62 & 0.07 \\
\hline DMF & $\operatorname{LiCl}(5 \mathrm{wt} \%)$ & 6) 30 & 30 & 65 & 0.10 \\
\hline
\end{tabular}


polyamide by the complex formation. Further study of this problem is planned in order to elucidate the reaction mechanism.

The polycondensation reaction of S, S-dipropyl dithioisophthalate with 4, 4'-diaminodiphenyl ether took place much more slowly than that of aliphatic diamine. Neither the yield nor the molecular weight of the aromatic polyamide were satisfactory, as shown in Table V.

Further studies on the polycondensation reaction of S, S-dithioesters with other nucleophiles such as diols or dihydrazides will be reported on in later papers.

\section{REFERENCES}

1. M. W. Cronyn and J. Jiu, J. Amer. Chem. Soc., 74, 4726 (1952).

2. J. C. Sheehan and D. A. Johnson, J. Amer. Chem. Soc., 74, 4727 (1952).

3. P. J. Hawkings and D. S. Tarbell, J. Amer. Chem. Soc., 75, 2982 (1953).

4. D. S. Tarbell and D. P. Cameron, J. Amer. Chem. Soc., 78, 2731 (1956). 